\title{
El papel del filósofo en la construcción del discurso moral
}

Víctor Hugo Salazar Ortiz

Departamento de Filosofía UAA vhsalaza@correo.uaa.mx

\section{Introducción}

Mark Platts, en la introducción a su libro Dilemas éticos, señala que se tiene la idea de que «el filósofo en tanto que filósofo puede ofrecer soluciones definitivas a los problemas prácticos morales» (1997; 9); sin embargo, él coloca esta clase de pensadores en una posición más modesta, pues cree que los filósofos pueden «colaborar en la resolución» de dichos problemas -no resolverlos-, sin que eso anule su aportación. ¿Cómo puede contribuir el filósofo en la resolución de los problemas prácticos morales? Esto es precisamente lo que me propongo revisar en este trabajo: señalar cuáles son los pasos que debe seguir el filósofo moral en su análisis y cómo a través de ellos puede colaborar en la resolución de los dilemas morales.

\section{I}

La primera tarea del filósofo moral es «reflexionar sobre el uso no reflexivo [de los conceptos] con el propósito de alcan- 
zar un entendimiento reflexivo de nuestra comprensión cotidiana no reflexiva» (Platts, 1997; 11). El objetivo de tal análisis es clarificar y ofrecer mayor precisión en la concepción de las ideas que suelen tenerse al calificar ciertas conductas o prácticas de índole moral, sin discutir si el término que se aplica corresponde en algún sentido a un juicio moral. Esto ocurre de manera cotidiana en el lenguaje ordinario cuando se califica una acción con un concepto que puede contener en sí mismo un sentido moral, pero éste no suele relacionarse con ese tipo de carga semántica, de manera que al emplearlo se parte de una «suposición» de sentido práctico; pero, si el caso lo amerita y se pide una justificación de su empleo, esto puede generar discrepancias y controversias. Por tanto, en el ámbito de la reflexión moral es imprescindible no pasar por alto esto, porque aunque resulte trivial en el lenguaje cotidiano, no lo es al momento de analizarlo bajo el ojo clínico de la ética, pues como señala Platts: «en casi todos estos debates [...] una gran parte de lo que está en cuestión es el uso correcto de ciertos conceptos en relación con nuevas circunstancias» $(1997 ; 11)^{1}$. Un ejemplo de esto puede ser el análisis del uso ordinario del concepto «cruel».

En el lenguaje cotidiano decimos que alguien es «cruel» o está realizando un «acto de crueldad» cuando no toma en cuenta el sufrimiento de otro(s) o perjudica los intereses de alguien, o causa un daño. Por ejemplo, alguien me puede decir que «es cruel no darle dinero al niño indigente»; o una adolescente puede decir: «mi padre es cruel conmigo porque no me deja tener novio»; o un empleado puede decir que su patrón «es muy cruel porque le paga muy poco»; o podemos decir «que algunos humanos son crueles con los animales».

Para una evaluación más profunda acerca de la importancia del análisis de los conceptos morales, ver Platts (2006). 
El concepto «cruel», sin embargo, implica algo más que perjudicar o dañar los intereses particulares de alguien (connotación que se le da en el lenguaje habitual), pero en sentido estricto y de acuerdo a su definición, debe ser aplicado a «quien se deleita en hacer sufrir o se complace en los padecimientos ajenos» ${ }^{2}$. Yo no creo que alguien se deleite al no darle dinero al niño indigente y esté de acuerdo con su sufrimiento, puede haber otras razones para justificar la omisión (como no traer cambio o pensar que así no se le ayuda). Tampoco creo que los padres que prohíben a sus hijas adolescentes tener novio, estén siendo crueles (aunque no descarto alguna excepción): tal vez tienen otras razones (impedir un embarazo; que su hija siga estudiando y no se distraiga; evitar una decepción o un engaño). En el caso del patrón se trataría más de un acto injusto que cruel (aunque tampoco descarto alguna excepción). En el tercer ejemplo la palabra «cruel» puede aplicarse apropiadamente -de acuerdo a la definición que se da de este concepto-, pues hay casos muy patentes en los que los humanos son «crueles con los animales». Tal situación es verificable en los espectáculos como las corridas de toros, las peleas de gallos o las de perros. Quienes asisten a estos eventos, efectivamente se deleitan y complacen con el padecimiento de unos seres que tienen suficientemente desarrollada la capacidad de experimentar dolor ${ }^{3}$. Los aficionados a estos eventos pueden argumentar que el término «cruel» no aplica en la relación hombre y animal, a lo que puede responderse que «los actos de crueldad son condena-

Diccionario de la Real Academia de la Lengua Española, versión electrónica: http://buscon. rae.es/draeI/ (énfasis del autor).

Para una revisión más amplia acerca de la aplicación del concepto de crueldad en animales puede revisarse el artículo de Regan, Tom (1998). Derechos animales, injusticias humanas. En Los caminos de la ética ambiental Teresa Kwiatkowska y Jorge Issa (comps.), CONACYT/UAM-i / Plaza y Valdés, México, 245-62. 
bles no sólo entre humanos, sino también cuando se llevan a cabo contra otros animales» (Herrera, 1997; 181). Además, si atendemos a la definición con mayor rigurosidad, vemos que señala que «ser cruel» implica la «complacencia hacia los padecimientos ajenos», no exclusivamente hacia el de los integrantes de la misma especie, de manera que «si un ser sufre -indica Peter Singer-, no puede haber justificación moral alguna para negarse a tener en cuenta este sufrimiento» (Singer, 1990; 44).

Éste es sólo un ejemplo, entre muchos posibles, de un concepto que se emplea cotidianamente, y cuyo uso poco reflexivo puede generar controversias morales con respecto a su aplicación. Es por ello que el análisis filosófico sobre los conceptos «es un prerrequisito en la resolución razonable del asunto en litigio» (Platts, 1997; 11).

La segunda contribución del filósofo para la resolución de problemas prácticos morales consiste en el análisis de las razones y los argumentos que presenta cada una de las partes involucradas en el litigio moral. Su colaboración consistirá en evaluar los argumentos de cada bando, y aceptar o enfatizar lo que parezca más consistente y sensato para la decisión que deberá tomarse en cada caso. Ahora bien, lo que suele ocurrir inicialmente en cualquier litigio moral es que cada una de las partes intentará deslegitimar los argumentos de su parte rival, aduciendo lo que a su juicio carece de consistencia. ¿Cómo superarlo?

Un primer inconveniente que puede darse en el intento de resolución de los problemas morales es que en el alegato se utilicen juicios viscerales que involucren sólo sentimientos 
personales; o juicios apoyados en tradiciones que avalan la realización del hecho en cuestión; o juicios religiosos que anteponen la legalidad divina a la humana y al hecho mismo. Cada una de las partes en conflicto puede presentar su exposición haciendo uso de estas fuentes, presentándolas bajo el supuesto de que son buenas razones y argumentos veraces. Sin embargo, no son ni lo uno ni lo otro, por tanto, no pueden establecerse como criterio para llegar a un acuerdo. ¿Por qué? Porque el origen de los sentimientos es irracional, pues se fundan en gustos y deseos personales, en tanto que las tradiciones y las creencias religiosas se fundan en prejuicios culturales. Entonces, tanto los sentimientos como los prejuicios culturales y religiosos empañan el debate moral y se convierten en un impedimento para ver objetivamente las cosas, y de esa manera provocan que no se pueda discernir con equidad y veracidad lo que es mejor, correcto o incluso lo más conveniente en un asunto moral que esté tratando de aclararse para su resolución. Es por ello que el análisis y la evaluación que realiza el filósofo de los razonamientos y los argumentos tiene una gran relevancia, pues como apunta James Rachels «no cualquier razón que pueda darse es una buena razón. Así como hay buenos argumentos los hay malos, y gran parte de la capacidad del pensamiento moral consiste en discernir la diferencia» $(2007 ; 34)$. No puede esperarse, entonces, que todas las razones y los argumentos que se presenten sean buenos, habrá algunos que sean dudosos y otros definitivamente malos, lo que será un impedimento para una discusión moral realmente razonable.

\section{III}

La evaluación de las razones y de los argumentos no es suficiente, se requiere apoyar lo que se dice con evidencias fácti- 
cas, esto sería el tercer paso. Para saber qué parte puede tener la razón, es necesario, además de los argumentos presentados, revisar los hechos, pues los problemas prácticos morales «no surgen independientemente de los hechos empíricos y contingentes que constituyen sus circunstancias: son problemas de este mundo [...] y sus soluciones tienen que ser soluciones para este mundo» (Platts, 1997; 12). Una visión real y clara de los hechos siempre debe tenerse en cuenta en la resolución de un conflicto moral. Una visión tal tiene como requisito la imparcialidad, es decir, no estar empañada por sentimientos personales o prejuicios sociales que limiten o impidan ver con claridad al filósofo moral la situación, asumir que «los hechos existen independientemente de nuestros deseos, y [que] el pensamiento moral responsable empieza cuando tratamos de ver las cosas como son» (Rachels, 2007; 34). En relación con esto, James Rachels señala que «casi cualquier teoría importante de la moral incluye la idea de imparcialidad. La idea básica es que los intereses de todos son igualmente importantes; desde un punto de vista moral, no hay personas privilegiadas. Por tanto, cada uno de nosotros debe reconocer que el bienestar de otras personas es tan importante como el nuestro» (Rachels, 2007; 35). En suma, tomar en cuenta los hechos y analizarlos de manera imparcial nos evitará caer en la arbitrariedad y cometer actos injustos en contra de otros.

\section{IV}

Una vez que se han establecido los hechos, el cuarto paso será aplicar los principios morales correspondientes. Los principios son guías de acción que nos indican qué debemos hacer, regular o generalmente, para que nuestra conducta práctica 
sea considerada moral. No obstante, habrá casos en los que tales principios manifiesten inconsistencia o sean contradictorios y, por ello, no resulte claro si debemos aplicarlos o no.

James Rachels, en su Introducción a la filosofía moral, nos presenta múltiples ejemplos de cómo puede ocurrir esto. Me permitiré tomar uno de ellos para ilustrar cómo puede presentarse un conflicto entre principios morales: el caso de las niñas recién nacidas Jodie y Mary (2007; 32, 33). La situación era la siguiente: Jodie y Mary son gemelas siameses y nacieron unidas por la parte inferior del abdomen, por lo cual comparten órganos vitales (corazón y pulmones), pero el funcionamiento de estos órganos es insuficiente para mantenerlas vivas a ambas. Se puede llevar a cabo una operación para separarlas y salvar a una de ellas. Sin embargo, los padres se oponen, aceptan la muerte de ambas porque sus principios morales les indican que si nacieron así es porque «hay una ley natural que debe seguir su curso»y «Dios así lo quiso». Los médicos tienen como principio el de «salvar vidas» y ven la posibilidad de salvar una; por tanto, consideran que lo más conveniente es hacer la operación, separarlas y salvar a una de las niñas. Entonces solicitan y consiguen un permiso de los tribunales para realizar la operación. Salvan la vida de Jodie, e intentan hacer lo mismo con la de Mary, pero al final ella muere, tal como estaba previsto.

En el caso presentado hay por lo menos otros dos principios a los cuales se podría hacer referencia, uno de raigambre utilitarista que señalaría que «se debe salvar la mayor cantidad posible de vidas», al cual se adhirieron los médicos y que parece ser lo mejor dada la situación, incluso haciendo uso del sentido común. Pero los padres de las niñas consideran que hay otro principio, de raigambre deontologista, que está por encima de aquél y es el de «la santidad de la vida», 
que nos obliga a respetar la vida de cualquier persona y por tanto no se le puede quitar la vida a nadie, a pesar de que de su muerte surja un beneficio.

En este caso hay todavía una pieza clave más, que mencioné de manera rápida, aunque es la más importante para la decisión que se tomó. Pareciera que fueron los médicos quienes resolvieron que la operación debía realizarse, independientemente de los principios morales que la impedían, sin embargo, ellos generaron esta opción y al final fueron sólo el instrumento, pues la justificación y la autorización para efectuarla provino de los tribunales: fueron los jueces los que optaron por hacer a un lado el principio clásico que prohíbe «matar seres humanos inocentes», pues en este caso específico no era aplicable, ya que con la operación no se anulaba la posibilidad de que Mary siguiera viviendo: ella ya estaba destinada a morir; tampoco se estaba utilizando su vida para salvar la de otra persona, como en el clásico dilema utilitarista del médico que tiene la opción de matar a un paciente sano y extraer sus órganos para salvar a cinco que los requieren para no morir (Harman, 2009; 305, 306). La muerte (inminente) de Mary permitirá a su hermana conservar su vida, intentar conservar la de las dos matará a ambas. Este caso demuestra que «no siempre es incorrecto matar a seres humanos inocentes. En situaciones excepcionales puede ser correcto» (Rachels, 2007; 27).

En este sentido señala Richard B. Brandt $(1982 ; 34,35)$ que la falla de los principios morales es resultado de sus pretensiones universales y de que se intenta resolver, por medio de ellos, situaciones que son especiales, de manera que atender a ellos tal y como indican que debe actuarse, resultaría incluso más inmoral que buscar otras opciones con mejores resultados. Para Brandt los principios morales pueden ser inconsistentes al menos de tres maneras: 
1) «Cuando los principios generales implican colisión en algunos casos posibles» (Brandt, 1982; 34). En el caso expuesto esto se da entre el principio de «no matar» $\mathrm{y}$ «matar para salvar una vida».

2) «Cuando los enunciados particulares no coincidan con los principios generales» (Brandt, 1982; 34). En el ejemplo expuesto se presenta en la conclusión: «no siempre es incorrecto matar a seres humanos inocentes. En situaciones excepcionales puede ser correcto». 3) «Cuando los enunciados comparativos no cumplen con la propiedad de transitividad» (Brandt, 1982; 34). Esto se da cuando se presentan varias opciones, en este caso varios principios opuestos, y todos ellos parecen ser el mejor, pero sin importar el que se elija, se cree que siempre habrá otro que es mejor. En el hecho narrado, y en muchos similares, sería cuando las personas dicen «Dios así lo quiso».

Los principios morales, como vemos, no operan como los principios científicos, no son fórmulas que puedan simplemente aplicarse independientemente del caso y resolver la situación; no pueden verificarse a través de la observación y la experimentación directa; tampoco comprobarse y calcularse matemáticamente (ver Harman, 2009; 13-20). Este hecho deja a la ética en una aparente situación de vulnerabilidad, en comparación con el trabajo desarrollado por las ciencias duras (física, química, biología), en las que los principios son plenamente operantes y responden de la manera en que se espera que lo hagan; si no lo hacen, se desechan. No podemos hacer esto con los principios morales, pues, siendo realistas, nos quedaríamos sin ninguno, o con muy pocos. De manera que lo que debe hacerse es buscar qué es lo que pue- 
de fallar en ellos e intentar corregirlo, y definir las principales características que deben contener los principios morales para justificar su aplicación y validez.

El profesor Richard Brandt detecta que la falla en los principios morales se da cuando éstos tienen la forma, «Haz siempre...», aunque este imperativo esté implícito en un principio moral. Por ejemplo, el quinto y octavo mandamiento de la ley mosaica establecen respectivamente que «no se debe matar» y que «no se debe mentir». Esto debe hacerse siempre, pero como ya vimos previamente, no siempre se puede cumplir ciegamente con el quinto mandamiento, y más de alguna vez es necesario emplear una mentira (por ejemplo para salvar la vida de una persona). Esto podríamos decirlo y ponerlo en práctica con muchos otros principios. Lo que el profesor Brandt propone para subsanar esta falla en los principios morales es que, «en vez de utilizar principios de la forma "Haz siempre...", podemos contar con reglas morales de la siguiente forma: "Siempre hay una fuerte obligación de hacer..." Así las propias reglas no especificarían qué regla ha de tener prioridad en caso de conflicto, dejando esta decisión al juicio de cada cual» (Brandt, 1982; 34). Esto es precisamente lo que hizo el juez en el caso Jodie y Mary: emitió su dictamen con base en lo que a su juicio tenía mayor prioridad en ese caso específico, independientemente de que hubiera principios opuestos.

Por su parte, Louis P. Pojman explica que «aunque no hay un acuerdo universal acerca de los rasgos que deben tener los principios morales, hay un amplio consenso acerca de cinco características [que poseen]: (1) prescriptividad, (2) universalidad, (3) prioridad, (4) publicidad y (5) factibilidad» (2006; 7). La prescriptividad indica que los principios morales se presentan generalmente como órdenes o imperativos y sirven para 
advertir a las personas e influenciar su conducta, también para premiar o castigar, y para generar sentimientos de satisfacción o culpa. La universalidad señala que los principios morales deben aplicarse a todas las personas que están en una situación relevante similar, es decir, que si alguien juzga que, lo que hace $\mathrm{X}$ con una persona $\mathrm{P}$ es correcto, entonces es correcto que eso mismo se haga con cualquier $P$ en todo caso relevante similar. En palabras más llanas, aplicar la regla de oro: «Haz a otros lo que quieres que otros te hagan a ti» y ser consistente con ella. La prioridad marca que los principios morales tienen autoridad predominante y prioridad sobre otros tipos de principios, por ejemplo, estéticos, jurídicos, prudenciales e incluso religiosos. La publicidad indica que los principios morales deben hacerse públicos para que puedan guiar nuestras acciones, lo cual permite que puedan usarse para prescribir comportamientos, además asignar alabanzas y culpas con base en su cumplimiento o incumplimiento. Por último, los principios morales deben ser factibles, o sea, viables y practicables, no una carga pesada que impida seguirlos y cumplirlos (Pojman, 2006; 6,7).

En suma, los filósofos morales, en su aspiración por aclarar qué es lo correcto, lo conveniente, lo justo, lo bueno, etcétera, en situaciones prácticas, requieren establecer una cierta metodología o sistematización que debe seguirse en el análisis moral. Los criterios pueden variar dependiendo del enfoque teórico que se les dé, pues hay distintas opciones teóricas que pueden seguirse en la resolución de los problemas morales (las principales son el utilitarismo y el deontologismo). Dependerá del filósofo moral cuál seguir, según lo que el caso requiera o sus criterios éticos, pero lo que no debe pasarse por 
alto es la revisión sistemática del problema, de manera que pueda ofrecer la mejor opinión para su resolución.

Bibliografía

Brandt, Richard B. (1982). Teoría ética. Madrid: Alianza Universidad. Textos.

Harman, Gilbert. (2009). La naturaleza de la moralidad. Una introducción a la ética. Cecilia Hidalgo (trad.). México: UNAM-IIF.

Herrera, A. (1997). Los intereses de los animales y sus derechos. En Platts. Dilemas éticos. México: UNAM- IIF / FCE.

LaFollette, H. (2002). Ethics in Practice: An Anthology. Blackwell Publishers, United Kingdom.

Platts, M. (comp.) (2006). Conceptos éticos fundamentales. México: UNAM-IIF.

Platts, M. (Comp.) (1997). Dilemas éticos. México: UNAM- IIF/ FCE.

Pojman, L. P. and Fieser, J. (2006). Ethics. Discovering Right and Wrong. U.S.A.: Cengage Advantage.

Rachels, J. (2007). Introducción a la filosofía moral. Gustavo Ortiz Millán (trad.). México: FCE.

Regan, T. (1998). Derechos animales, injusticias humanas. En Teresa Kwiatkowska y Jorge Issa (comps.). Los caminos de la ética ambiental. México: conacyt/uam-i / Plaza y Valdés. Singer, Peter. (1990). Liberación animal. España: Trotta.

Resumen

La ética, entendida como filosofía moral, estudia el sentido general que tienen los códigos morales y genera los elementos metodológicos y conceptuales que permiten juzgar críti- 
camente su validez. El principal objetivo de la ética es, por tanto, asumir una perspectiva reflexiva y señalar los alcances y las limitaciones de sus principios en circunstancias concretas. Lo que se revisará en este trabajo es cómo debe construir el filósofo el discurso moral.

Palabras clave: ética, moral, filosofía moral, dilema, resolución.

\section{Abstract}

Ethics or moral philosophy studies the general sense of moral codes, and generates the methodical and conceptual elements that allow us to judge critically their validity. The main object of ethics is, then, to assume a reflective perspective and point out the reach and the limitations of their principles in particular circumstances. This paper examines how philosopher has to build the moral discourse.

Key words: Ethics, moral, moral philosophy, dilemma, decision. 
